\title{
Witnessing Change: Understanding Change in Participatory Theatre Practice with Vulnerable Youth in a Kids Company Supported Primary School
}

\author{
Nicola Abraham¹, Royal Central School of Speech and Drama, University of London.
}

\begin{abstract}
:
This article details key findings from a longitudinal study conducted in collaboration with Kids Company, funded by the Arts and Humanities Research Council. (AHRC). The focus of this article is the role of the 'teacher as witness' to the impact of a participatory theatre project with vulnerable young people. This research argues that the opportunities afforded by challenging pre-emptive constructs of vulnerable youth held by a teacher, can enable changes that take place within a workshop, which can often remain temporary and confined to the space and time of a project, to transition back into the wider school environment. Drawing upon the concept of witnessing discussed by Laub and Felman (1992), Rymaszewska (2006), Gerhardt (2004) and Coady (1992, 2002), this article proposes that witnessing change can offer a means of sustaining impact. Insights into this proposition are offered in an example case study analysis of a project I conducted within a Kids Company supported primary school setting in Lambeth, South -East London.
\end{abstract}

Key Words: Kids Company, Participatory Theatre, Vulnerable Youth, Witnessing, Change.

\section{Word Count: 8,388 exc. Abstract.}

\section{Introduction:}

Participatory Theatre has a history of claiming change as an effect of participant-centred interventions. Michael Etherton (2006), James Thompson (2009), Michael Balfour (2009) and Sheila Preston (2009) have critiqued these claims inviting a reassessment of whether or not change is possible. They also question the neoliberal agenda that applied theatre practice might serve, and remind us that we cannot force change to happen, but should perhaps instead value the little changes that may accidentally occur within or after our projects have taken place. In this article, I aim to address these points through a case study that offers new insights into the potential of forum theatre to provoke change within the lives of vulnerable inner-city children. Between 2008 and 2011, I undertook an AHRC-funded collaborative doctorate with children's charity Kids Company. Kids Company provided street level support centres, and teams of therapists in schools in deprived areas of London offering a range of services to support children who had experienced neglect, deprivation or trauma in their lives. My research within Kids Company centres and schools explored the potential of participatory theatre to create opportunities for change in the lives of vulnerable inner-city children. The research was practice based, and I took on the role of practitioner researcher working in Kids Company partner schools and crisis centres settings. Here, I privilege one of the most significant moments in my research that took place in a forum theatre performance in a primary school. Boal's forum theatre has critics. Tony Fisher (2011) asserts that radical democratic theatre is plagued with limitations that may inhibit its efficacy as a tool for transformation, for example. I would like to propose that it is not the methodology that is at fault, however, but the circumstances of the invitation for 'spectactors' to intervene and arrive at a point of realisation that may need adjustment. I will offer a consideration of a short piece of forum theatre, devised by a group of six 9 to10 year old children in a primary school in south-east London. I will propose that the role of the class teacher as witness and the students as 'co-witnesses' to moments of 'change', may offer the potential for change(s) to exist beyond the lifespan of a project. In this article, I will discuss this idea in relation to a moment of change that occurred in

${ }^{1}$ E-Mail: Nicola.Abraham@cssd.ac.uk 
an impromptu forum performance. The forum performance presented an incident that took place in a classroom.

\section{Participatory Theatre and Issues of Change}

Kees Epskamp offered a series of case studies investigating interventionist and participatory models of Theatre for Development (TfD) noting that this approach has:

[...] certainly played an intervening role in social development and change. Some of these initiatives were merely intended to direct part of the population in a particular direction and thus change it in a modest and efficient way $(1989,171)$.

Epskamp offers a tentative claim here noting the potential of both exogenous and endogenous models of intervention and how they may both offer possibilities for change to exist. His main point is that theatre can educate, can awaken critical thought and provide avenues for change to take place. In 2004, Syed Jamil Ahmed offered a counter point to Epskamp's claims by noting that TfD models of practice adhering to the agendas of NGOs enforces a neoliberal agenda on impoverished communities. He continues by stating that naming participants as subjects as opposed to objects of development implies a western construction of selfhood has been enforced on participants. The assumption that theatre has an impact and that said impact is measureable denotes a clear drive towards a desired goal for a TfD intervention, leaving little room for participant choice and agency in processes deliberately set up to provoke change.

Tony Fisher argues that Boal's approach to enabling change through rehearsed actions stems from his belief in the 'emancipatory potential of theatre' to enable 'freedom from oppression' through liberating the spectator to become an active agent for change (Fisher 2011, 15). Fisher's criticism of Boal resides in his argument that Theatre of the Oppressed (TO) may not 'liberate' audiences, but that what Fisher terms radical democratic theatre, can potentially 'destabilise' conditions that may have led to oppression. If theatre can offer a space to challenge social constructs that are considered to be oppressive, then it may be possible to change audience perceptions and even their actions. This form of destabilisation could offer a more effective application of Boal's practice specifically for children and young people.

Children and young people are governed by the rules of adult society, they are bound by rules and expectations, even if they are to their detriment. In an interview with Robert Landy and David Montgomery, James Thompson describes a conversation he had with a youth theatre director about the importance of theatre for young people as a means of challenging society:

I'm not interested in theatre that changes young people, but in young people creating theatre that expresses the changes they would like to see. They don't need to change, society's response to them does (Thompson in Landy 2012, 232).

Thompson's recollection shifts the rhetoric of expecting change from young people, and the importance thereby of using theatre to change society's response to them. Henry Giroux details society's response to young people in his book Youth in a Suspect Society: Democracy or Disposability (Giroux, 2010). Here he points out grimly the emergence of a demonising construction of young people on the margins of society as a risk to the consumer driven neoliberal order:

Those young people... who resist the seduction of the commodity market increasingly fall prey to the dictates of a youth-punishment-and-control complex that manages every aspect of their lives and increasingly governs their behaviour through modalities of surveillance criminalisation $(2010,14)$.

Giroux continues to describe the role of the media in furthering discrimination and fostering low expectations of vulnerable young people as 'lazy, stupid, self-indulgent, volatile, dangerous, and manipulative' (ibid.:14.) Narratives of blame have become synonymous with 
vulnerable inner city youth. Terry Potter and Graham Brotherton draw upon the work of Ulrich Beck to argue that it is unsurprising that narratives of blame cause young people to respond:

We are arguing that vulnerability is created by a complex interconnection of social circumstances and should not be seen as arising from mistaken or misplaced individual behaviour, decisions or fecklessness. Indeed, it can be argued that some of the behaviour of vulnerable groups which is often perceived as problematic can be constructed as a rational response to very difficult circumstances (Potter \& Brotherton 2013:10).

Potter and Brotherton's reading of challenging behaviour offers an instance that may be described as a manufactured Pygmalion effect. By this I am suggesting that government cuts to youth provision, and infiltration of neoliberal values into the education system, actively seek to exclude and alienate vulnerable inner city youth. In reaction to pressures to achieve and the often complex socio-economic circumstances that may prevent a young person from achieving, a reaction of disengagement, frustration, and ultimately exclusion from an unjust, alienating system may follow. This process has been witnessed and documented by a range of sociologists examining the lives of low socio-economic, vulnerable or excluded youth (see Macleod 1987; Bourgois 2004). How then might we interrupt this process of constructing low expectations through theatre?

Hope that participatory theatre forms could provoke change have been reawakened by Eva Österlind's assertion that change may need to happen on an individual level before seeking a broader social shift. Österlind's article suggests that Boal's Forum Theatre may offer points to expose what Pierre Bourdieu terms 'habitus', a set a habitual attitudes and behaviours formed through processes of social reproduction (2008). Within this cycle, the child learns from their parents how they are perceived by the world and how to respond to this perception. This process is further reinforced by teachers who transfer their expectations of success or failure on to their students. An opportunity for change may be afforded through unpacking a set of seemingly 'natural' circumstances, and enabling participants to recognise that they are in fact constructed rather than 'just the way things are'. However, the participant must also make a choice to change or not to change, which must be respected by the practitioner. This approach still does not guarantee change as an outcome of participatory theatre, but it does offer an arguably more realistic expectation of theatre for change.

Michal Balfour further develops this idea calling for a theatre of small changes, acknowledging the accidental findings that may occur when resisting broader practitioner and donor agendas for social change, rehabilitation and behavioural improvements. Balfour also acknowledges that more may be found in the unexpected if we:

[A]cknowledge that what applied theatre does is not always linear, rational and conclusive in its outcomes, but is more often messy, incomplete, complex and tentative (Balfour 2009, 357).

In other words, if we change our expectation that change will happen if we employ a different approach, we may awaken a more responsive practice that listens to the value participants place on their experience of the project rather than claiming our own indicators of efficacy. It also importantly suggests that change is not a formulaic theatrical process, but a series of small victories and points of celebration. I wish to reflect upon what may be described as a 'little change', and certainly speaks to Balfour's criteria of an unexpected, unplanned and accidental outcome. This moment may offer insights into the importance of choice as an act of agency that needs to be apparent if change is to transition from a workshop to a classroom without the requirement needed for 'sustaining change' through continued interventions.

\section{Methodology: Taking a Pluralistic Approach}

The focus of this article is a workshop that took place in a primary school with two classes per year group in South-East London within the borough of Lambeth, ranked as the 14th most deprived area of the UK (Lambeth Council, 2012). Children who took part in the project 
accessed Kids Company support in the form of arts therapy and mentorship, which was offered to help create a safe space to discuss difficulties happening at home. Upon embarking on the project the lead Arts Therapist Team Leader for Kids Company stated that the school was fragile at that time due to a recent increase in gang-related shootings in the area, which had left to the death of siblings and parents of children who attended the school.

The project explored the topic of difference in reaction to increasing levels of racism, violence and abusive language present within this particular cohort of young people. Workshops took place with 12 children, six from each form group in year five classes (aged 9$10 y r s)$. They were allowed time out of the classroom to take part in the project. Class teachers therefore did not attend the workshops. Children who took part in the research were selected through consultations with their class teachers, a Kids Company Arts Therapist who supported the children, and the inclusion/child protection officer for the school. Children were selected based on the following criteria:

- Poor interactions/relationships with peers.

- Tendency to bully, be bullied, use physical violence and verbal aggression.

- At-risk status - likelihood of school exclusion, self-harm, unstable home environments.

- Would benefit from taking part in six weeks of intensive small group exploratory drama.

Children were also given the option to take part if they wanted to, once an initial selection had been made using the criteria outlined above. An Office for Standards in Education, Children's Services and Skills (OFSTED) report on Greenlake school documented the demographic of the school as $25 \%$ White British, with a wide range of minority groups, the largest noted was Black or Black British-Caribbean and Black British-African $(2014,3)$. The gender split in the two groups was 5 male $(M)$, and 7 female $(F)$ (group $1=3 \mathrm{M} / 2 \mathrm{~F}$, group $2=$ $2 \mathrm{M} / 4 \mathrm{~F}$ ). The names of the school and children who took part in the project have been changed to ensure their anonymity. Code references have been used for the case study group, group 1: Taylor (F), Mina (F), Greg (M) Devan (M) or Daniel (M) have been given to identify different participants. The names of teaching staff (Miss Ford and Mr Green), and the Arts Therapist (AT) who took part in the project have also been changed, and are referred to as Miss Ford, Mr Green and Mrs Rubens. It is important to note that Mr Green was the class teacher for the workshop discussed in this article. Miss Ford's students took part in the same project. Mr Green witnessed the final workshop for his group when he happened to have a planning afternoon and his students invited him to see their performance, Miss Ford did not attend any workshops.

An important intention for this research project was to ensure that a range of perspectives were captured to understand changes in relationships within the group dynamic and between the class teachers and their students. The aim of capturing multiple perspectives is two-fold:

1.) To capture the plurality of voices in the research process to understand possible 'impacts' and/or 'changes' that have taken place.

2.) To juxtapose and engage with different readings of the value of the practice to understand how witnessing change relates to the process of creating sustained 'impact'.

Sharon Grady places emphasis on the importance of capturing multiple voices within research processes noting, most importantly, the need to ensure the perspectives of those directly affected by the research are incorporated into the process of understanding what happened within the workshop in question (Grady 2000). Ethnographic approaches were employed to gather empirical data to capture any transitions of change. In addition, to document the project, I used a range of methods including thick description journal entries from the researcher/practitioner, feedback forms, qualitative and quantitative questionnaires, verbal discussions with participants, teachers and the Kids Company arts therapist, and conducted interviews with those who 'witnessed' the process. 
The challenge of noting subjectivity, as a researcher and practitioner directly involved in the research process is also useful to recognise. Kim Etherington suggests that 'Reflexivity is... an ability to notice our responses to the world around us, other people and events, and to use that knowledge to inform our actions, communications and understandings' $(2004,19)$. Triangulating research findings from thick descriptions of workshops, interviews and questionnaire responses provided a means of capturing a range of readings of the same event (Denzin \& Lincoln 1998). This approach additionally offers a process of verification to compare the outcomes of qualitative data gathering strategies to generate grounded theory i.e. substantiate claims about the outcomes of the workshop. The next section will provide an example moment of practice and analysis, which demonstrates the potential of witnessing as an opportunity to create change. In this case, change refers to presenting a challenge to preemptive constructs of vulnerable children held by their teacher.

\section{Case Study: Greenlake Primary School}

In the case study example of Year 5 workshops at Greenlake Primary School, participants' behaviour towards one another changed dramatically during the third workshop of the project. For the first time in the process participants had contributed their own stories about difficulties they faced in the classroom. The group created the following scenes exploring difference through short improvisations in response to the following: 'a time when people got me wrong'. ${ }^{2}$

\section{Scenario One:}

During the first performance Greg, Daniel and Devan performed a story of a new boy who arrived in a classroom for his first day and immediately wanted to stamp his authority within the space by throwing around the books of the other two pupils. Unfortunately his attempt at stamping his authority over the group lead to further problems as the pupils retaliated, which lead to a staged fight. I was asked to step into the action in role as the classroom teacher at this point. I entered the space and asked the boys what was going on at which point they informed me that Greg's character had thrown their books out of their hands. I asked Greg who he was and whether or not this was true, to which he responded by feigning ignorance, the boys continued to explain his actions until Greg eventually admitted his guilt.

\section{Scenario Two:}

Finally, Taylor and Mina entered the stage area and presented a short scenario where Taylor was playing in the playground on her own and Mina asked her whether or not she could join in. Taylor said that she couldn't because she just cried and messed about all the time. After each scene I joined the group on stage and asked whether the audience could think of any interventions that could be used to change the outcome of the scene. Each group tried several suggestions and to my surprise accepted one another's ideas as viable solutions. The class teacher joined in to offer a suggested solution to the scenario, which was facilitated by Taylor. At the end of the performances the group applauded one another, as the teacher left to go back to class he told everyone that they were very good.

It was most unusual for the group to accept one another's ideas: they often blocked suggestions from those they didn't like within the group. This was an unexpected progression. In previous workshops several participants refused to stand near one another, nor would they accept or answer questions that I posed to them about the content of the improvisations they had created.

It is significant that the class teacher was present in this workshop. His presence was requested by the group. The teacher attended the performances and saw for himself the progression of students who he had informed me could not work together, nor show any sense of leadership or empathy. A significant moment that is essential to state is the confident

2 'Do you get me?' and 'You got me wrong' were phrases often used by participants. They are the colloquial equivalent of 'do you understand me' and 'you have misunderstood me'. 
performance given by Taylor, who was the least self-assured of all the participants. After her performance (Scenario Two), I was preparing to stand up to facilitate a debate when she signalled me to sit down and proceeded to facilitate alone.

A debate ensued about the most realistic compromise that could be made by Taylor's character to ensure that the scenario had a positive outcome. Perhaps the most unexpected change in behaviour was Devan's contribution that was incorporated into Taylor's performance as a suggested intervention. This was a significant moment for Devan, who up until this point had not spoken to Taylor unless it was to make a racist comment. Taylor had also behaved abusively towards Devan by avoiding him and stating upsetting comments, which on occasion caused retaliation. During the enactment of Devan's intervention, Greg and Daniel began talking and were promptly told to be quiet and listen by Devan. This moment marked the end of a temporary shift in behaviour, and I expected Daniel and Greg to retaliate and a verbal fight to commence. In opposition to my predictions, Daniel and Greg responded with a slight grimace, but nevertheless listened to Devan and focused, albeit momentarily, back on the performance.

This shift is important not just because of the change of interactions between participants, but more importantly, this was witnessed by the class teacher, who had previously described the students who took part in the project as follows:

That kid is emotionally retarded

He doesn't have anything to say

She never takes part

He can't feel empathy

No one likes him (Mr Green, \#Journal Extract 1).

It is often frustrating that change in attitudes or interactions take place in isolation, away from the classroom, and are not witnessed by teachers. Despite giving regular reports to teachers about the changes in interactions between participants within workshops, hearing about an event, and witnessing it have two completely different impacts. Reporting back shifts in behaviour could potentially alter the teacher's expectations of participants; however, there is a level of suspicion surrounding outsider interventions, which claim to enable change to take place. For example, after every workshop I would update each class teacher on the interactions between their students. However, moments of understanding and compassion between group members were dismissed with responses such as 'Well, they are just in the honeymoon period' rather than acceptance (Miss Ford, Journal Extract \#1).

Breaking cycles of 'expectation' towards vulnerable youth may be the first step towards preventing self-fulfilling prophecies reinforced within institutional settings such as schools. Presenting opportunities for young people to play with and challenge constructs held by those with whom they have significant contact, for example, teachers, within the education system, may create opportunities to prevent the continued Pygmalion effect of reinforced pre-emptive constructs that inhibit vulnerable youth through institutional discrimination. Coretta Phillips discusses institutional discrimination against minority and working class children within the education system (Phillips 2011). Phillips draws upon the work of Diane Raey who discusses the historical pathologisation of white and minority working class young people, who Raey suggests have been described as: 'unmotivated, unambitious and educational 'losers' set against middle-class 'winners' (Raey 2008, 2009, in Phillips 2011,182). Raey's suggestion that the historical grounding of cultural and class stereotypes is prevalent in contemporary educational institutions and teacher responses, may provide a rationale for the constructs of blame and shame communicated from teachers to students and the resistance of students towards institutions exhibiting discriminatory practices. Raey continues to suggest that the actions of teachers greatly impact the life trajectories of the working class young people they teach: 
Decision-making by teachers - for example, choosing not to fully support and educationally challenge an individual pupil - may be influenced by these generalised and imprecise representations....which has a deleterious effect on pupils' school careers and later employment opportunities $(2011,182)$.

The necessity to challenge these preconceptions is of paramount importance if we are to begin to lift the limits imposed on vulnerable youth. From Raey and Phillip's discussion, we can see that incidents of low expectation and dismissive behaviours from teachers towards their students are not isolated incidents specific to one school, they are a society wide challenge to address. That this challenge is not a 'one-off' incident, brings with it further urgency to understand how participatory theatre might change low expectations, which clearly have a negative impact on the lives and self-perception of vulnerable young people.

\section{An act of child agency?}

Changing interactions in a way that contradicts the class teacher's perspectives of their students, challenges the personal constructs the teacher holds. Burton Clark argues that the teacher/student relationship provides insights into the importance of challenging pre-emptive constructs:

[F]or as long as a sizable share of the children from culturally deprived and lower-class backgrounds are dirty, violent, and unmotivated - or appear so in the eyes of their teachers - the teachers are likely to handle them differently, teach them less, and want to escape (Clark 1962 in Rosenthal \& Jacobson 1992, 52).

The pressure on teachers to support young people facing deprivation and trauma in its various forms, is difficult, particularly when working with groups of 30 students. Within this particular workshop new expectations were formed and acted upon by the teacher. Mr Green praised his students for their efforts and not only invested time witnessing their work in action but joined in too. This moment is significant. It marks a point where Mr Green directly saw the ability of his students to interact less aggressively and dismissively towards one another by working together to resolve problems. For example, Taylor's actions displayed her ability to join in, lead group discussions, to add value to others' ideas and to create resolutions to problems she and other participants encountered both in the playground and outside of school. The choice of the group to change their usually dismissive interactions with one another at the start of the workshop and to continue within the presence of the teacher, demonstrates their use of agency. Allison James and Alan Prout discuss the shift in understanding what constitutes child agency through their engagement with interpretivist sociology which suggests that children are creative agents (actors) producing new cultures in childhood (2015). This rejection of reductionist biologically determined roles for children as undersocialised apprentices to adult behaviours marks a shift in theoretical constructions of childhood. Indeed, Taylor's actions can be explained through a reconciliation between structures within the school and agency asserted by the participant. Anthony Gidden's structuration model is useful here to understand the significance of child agency as an act of change:

Every act which contributes to the reproduction of a structure is also an act of production and as such may initiate change by altering the structure at the same time as it reproduces it (Giddens 1979, 69).

Gidden's theory provide as useful frame to understand how Taylor' choice to take on a leadership role in support of her peers in group 1 may be seen as an act of agency, but it may also be seen as reproducing an expected institutional structure of behavioural expectations i.e. she is adhering to the rules of the school by supporting her group. However her act is also political - she has arguably chosen to assert her agency by 'acting' against the initial constructs of her teacher. It is interesting that despite the group opting to take part in the workshops they were also aware that they were selected for the project for other reasons. They identified commonalities between themselves as a cohort several times in the project and asked why they were selected, before answering their own question with clear 
understanding that they were usually the students who were sent out of the classroom or in trouble in the playground. This context makes the moment in question more significant as an act of agency within a structure. It is also possible that the teacher's choice to participate and become an active witness of this moment of agency further changes the structural reproduction by obtaining knowledge of new expectations of the abilities of this group of children.

This does not mean that participants have not previously demonstrated agency in their interactions with one another and with their teacher, though the form of their previous actions usually led to suspensions from school or being asked to leave the classroom to calm down. It could be argued that this behaviour is an effect of the cycle of social reproduction formed and maintained by educational structures, habitus, and the transference of low expectations. This would suggest that participants' previous interactions within the classroom were not an act of agency but a reaction to institutional exclusion. The significance of the communication of a more positive supportive group dynamic, which disrupts previously held constructs, is in effect a more obvious act of child agency. The participants' choice to display signs of agency in the presence of their teacher as a witness, and his positive reaction in response, may have affected the possibilities for change presented by the project.

\section{Discussion: Witnessing Change - Teacher as Witness}

There was a noticeable increase in the observed levels of confidence and self-esteem presented by participants, which were essential elements in the process that may have enabled participants to feel able to perform constructs that were in opposition to those held by their class teacher at the start of the process. Participants' feedback from both groups demonstrated that they enjoyed the workshops, which were identical in design but often modified between groups if feedback indicated that a particular exercise was not working or needed to be longer. Feedback about the longer term impact of the project was collected one term (13 weeks) after the project finished. Initial participant hesitations to communicate problems being faced in the classroom were overcome, which was evident in their willingness to perform personal experiences at school and move away from the fictional exploration of conflict and difference offered by the original stimuli for the project. This change is noted by the class teacher in his feedback:

\footnotetext{
...the materials provided although fictional were able to prompt the children to talk about "real-life" situations/problems (Mr Green, July 2009).

I think this is useful so like if, if it was someone else being my role - the person that's being bullied - they'll know how it feels if they bully someone else (Participant Responses, July 2009).
}

Participants and Mr Green noted the importance of performing real life scenarios to enable their peers to shift their constructs of what it feels like to be in another person's shoes. Their feedback suggests the potential for empathy to change peer interactions. Empathy as suggested by Asha Singh is a process of humanisation. Singh argues that theatre offers important points of understanding to navigate tensions between social diversity and academic conformity through exploring identity constructions and opening avenues of understanding (2004). The initial stimuli for the workshop series in this project was based on the story of Wicked: The Life and Times of the Wicked Witch of the West by Gregory Maguire. Workshops explored ideas of injustice, inequality, difference and hope. Each workshop explored a particular challenge faced by the Green Witch, and intended to use improvised scenarios to hot seat key characters, build empathy from the group towards the Witch, and develop a parallel narrative to the challenges of understanding difference the participants were displaying in their relationships with their peers. The final workshop offered participants the opportunity to continue playing with the scenarios in the story or to move beyond the fictional world into their own experiences at school. The group chose the latter option and explored a number of scenarios where they felt excluded or wanted to portray a moment of injustice they had experienced. The intention of this final session was for the group to self-solve the problems in 
the real world from the knowledge they had developed from helping the Green Witch in the fictional world. This may explain the shift in perspectives noted by Mr Green and the participants. In this case the group chose to collaboratively solve one of the problems that troubled them most, being blamed for something they hadn't done, by inviting their teacher to solve the scenario with them. This indicates an intention to want to provoke empathy through demonstrating an injustice to the person who caused this incident to happen. It also shows courage, and a sense of belief in their ability to problem solve together with a teacher who has clearly stated his low expectations about these children. This may also be read as empathetically attempting to give the teacher a second chance to see his decision in a 'better' way. This asserts a belief in the ability of the teacher to change his behaviour given the opportunity, much like the characters we had explored in the fictional world, and the dynamic changes that had enabled friendships to form between participants.

To offer another perspective on the impact of the project I conducted an interview with the Kids Company Team Leader at Greenlake School, who helped coordinate the project. She had also witnessed and taken part in several workshops in addition to conducting verbal debriefs with my co-facilitator and I after each workshop to keep up-to-date with the process and disclosures. The section of the interview that I have included below is in response to the question: Do you think that the young people who took part in the projects have benefitted from the interventions?

\begin{abstract}
I think they've hugely benefited from the interventions... Learning to express your feelings, learning to look at why I feel like that, you know questioning things about their day to day lives... And I think actually the teacher benefited a lot by being able to observe their class interacting with one another in seeing them from a different perspective, so I think the children would have benefited from their teacher getting a fresh perspective on the pupils as well (Mrs Rubens, July 2009).
\end{abstract}

Both the teacher's and the participants' responses suggest that constructs may be changed if someone is surprised, or shocked by what they witness. George Kelly's theory of personality, personal construct theory, offers insights into how constructs may be challenged and how they are secured. More recent authors have engaged with Kelly's approach) expanding the application of a social constructionist approach to understanding the way we see ourselves and others, however I would like to return to the original points Kelly offered to help us understand how constructs are created, and how they can be changed (see Bannister 1985). Kelly's theory can help unpack Mr Green's reaction by suggesting that in order for a perception/expectation to be confirmed, the student will have to be seen behaving in a manner that supports the construct held by the teacher and vice versa (Kelly 1963, 154). Kelly outlines two particularly relevant dimensions of constructs:

- A Pre-emptive Construct is one which pre-empts its elements for membership in its own realm exclusively - for example, species names.

- A Constellatory Construct is one which fixes the realm of membership of its elements - for example, stereotypes $(1963,156)$.

Kelly's approach arguably discusses constructs in relation to freedom noting the possibility of choice relative to how we construct others and our experiences. Pre-emptive constructs associate meaning with expectations of attributes belonging to an object or subject. This is a form of pre-judgement such as low expectations of attainment from vulnerable youth (Smith 2011; Muncie 2009). A constellatory construct names associated ideas to people or experiences informed by a number of factors. For example, a teacher in a classroom faced by consistent absences and poor behaviour may begin to construct an expectation of a pupil to be disinterested in education. Subsequently, subtle changes in the teacher's construction of the child may be projected and felt by the child, which may further affect and reinforce their behaviours. Though constructs can manifest as 'unchangeable certainties', this isn't the case. When a construct is disproved i.e. an event occurs that contradicts a construct, the previously 
held 'certainty' is forced into a state of doubt. This is because an exception can create space for a change in perception and, as in the case study example discussed, offers an alternative construct. One that is more beneficial for both the teacher and his students.

Kaethe Weingarten explores the notion of common shock (small unexpected interactions) as a process of witnessing that occurs in everyday life. Weingarten offers insights into the possibilities of intentional witnessing where deliberate intervention aims to provoke compassion and understanding (2003). This presents interesting possibilities in how we think about and enable change to happen. The position of witness is particularly interesting in relation to the proposition of inviting witnesses from outside a project to watch and observe: as active witnesses, observing interactions may provide moments of common shock. Witnessing interactions that are unexpected can provoke the invited witnesses to reconsider their established views of participants. This process may then provide a lens through which to understand, and capture how change may transition.

In the case study example within this article the reaction of the teacher, who witnessed his students 'acting' against his initial constructs, may account for the differences of interactions he communicated to me 13 weeks (a term) after the project had taken place in comparison with the second teacher, who had not witnessed her students, and reported little change. Mr Green, in his follow up conversations with me told me that the students in group 1 had chosen to sit together around the same table in the classroom. He also informed me that Taylor often put her hand up to respond to questions in class, which she had previously declined to do, and the group seemed to support one another and generally contributed much more to class discussions. The statistical evaluation results further support this reading by indicating that the involvement of both teacher and students in interventions is important to the successful sustainability of changes in interactions beyond the lifespan of the project. Quantitative results showed that the 'success' rating of workshop outcomes for the category of confidence building were rated as 5/10 for Miss Ford, and 7/10 for Mr Green, similarly the category of increased self-esteem was rated as 5/10 for Miss Ford and 7/10 for Mr Green. This increased result $(+20 \%)$ may be attributed to Mr Green witnessing his students 'acting' against the constructs he communicated at the start of the project, showing a noticeable difference in impact results. But besides a difference in results, what is most significant here is that Mr Green noticed a change in his students. He noticed they were capable of something beyond his initial expectations, which as I noted, were rather limited and dismissive of the abilities of the 6 children who went on to challenge his reading of them through their performance.

The role of the teacher as an active witness rather than a spectator to the performance thereby seems vital to understand how change may transition beyond a project intervention. Caroline Wake discusses active spectatorship regarding the possibilities of the co-presence of both spectator and performer where:

$[T]$ he figure of the performing witness refers to the observer who becomes so ethically and empathically engaged in or by a performance that he or she is transformed from a passive watcher into an active witness $(2008,188)$.

The change of the spectator to a co-witness, whose presence acts to value the experience communicated by the teller/performer, is, according to Wake, taking part in an act of witnessing. This places the spectator in the position of the instigator of an interactive exchange, which values the knowledge shared by the performer/teller, allowing, accepting and creating opportunities for the experience to impact upon all present in the company of the teller as co-witnesses.

The role of the witness can be traced to testimonial literature, which recounts the importance of witnessing as an act where 'a witness is a witness to the truth of what happens during an event' (Laub \& Felman 1992, 80). Dori Laub and Shoshana Felman offer a psychoanalytic reading of the role of the witness. They describe the witness as an 'author and ventriloquist for the object world adding nothing but his mere opinion' $(1992,85)$. This 
statement challenges the link between witnessing and truth. The position of a witness necessitates that their perspective of an event is a subjective reading of what was encountered, making truth claims problematic. In response to this concern Laub and Felman attribute value to the act of internalised witnessing. This can be seen when a witness recounts an experience. In this case she is witnessing him/herself by reclaiming and "reconstituting the internal "thou" and the possibility of a witness or a listener inside himself' (ibid, 85). This positioning seeks to establish that the person giving testimonial accounts is self-observing, and claiming authority over her own experience. In this example, there are multiple witnesses present who also encounter and experience the value of the testimony being given:

What ultimately matters in all processes of witnessing, spasmodic and continuous, conscious and unconscious, is not simply the information, the establishment of the facts but the experience itself of living through testimony and giving testimony (Laub \& Felman 1992, 85).

Here Laub and Felman note the significance of the process of witnessing. The process of sharing an encounter between the witness and the listener is, according to Laub and Felman, a means of enabling the teller to re-witness herself in a process of recounting an experience. The value of retelling the experience is in the self-witnessing that takes place. The significance of this reading of the witness is apparent within the work conducted by Kids Company. Camila Batmanghelidjh, Kids Company's founder, has written of the importance of co-witnessing childhood and recognizing how neglect, abuse and trauma carries value for vulnerable youth. In this sense, the process of witnessing or co-witnessing is a way to help vulnerable young people cope with traumatic events by re-establishing an internal witness (2006). Similarly, the teacher as witness to performance of his students becomes a co-witness to their ability to move beyond his preconceptions. His role as witness and their role in witnessing him responding positively to their work is essential to create a point of change, or authentication. This perhaps explains why feedback without witnessing students directly leads to dismissive reactions to change observed in workshops. Direct co-witnessing has the opposite effect, providing the witnesses of the workshop with self-observation and an ability to claim ownership over their encounter without a third party (absent teacher's) interpretation.

This is a process echoed by Teya Sepinuck in her book Theatre of Witness. Sepinuck defines bearing witness as 'to "be with" fully and compassionately' $(2013,228)$. In this sense witnessing allowed the teacher and his students, in the act of seeing and listening, to connect with the events they are encountering. The location of value in this scenario is through acknowledgement. The acknowledgement could be perceived as the teacher's willingness to be involved in the performance facilitated by Taylor to help resolve the scenario. It could also be seen in his praise, which he shared with the participants as he left the space. This may have been a pivotal moments for the group who are used to being in trouble in class. Participants gaining praise and seeing their teacher, who usually sent them out of the classroom, suddenly joining in with their performance and congratulating them for their work arguably demonstrates an act of compassion: One that may have been responsible for the feedback from Mr Green, which suggests a continuation of positive interactions between participants back in the classroom.

Witnessing in itself is something that is missing from the lives of vulnerable children as they develop, which appears to be the case for many young people who experience neglect. Janie Rymaszewska states the importance of witnessing a child's story in order 'to empathise with the child and affirm the validity of [his/her] experiences' $(2006,57)$. Sue Gerhardt agrees with this point, discussing the presence of a caregiver to respond to the needs of the distressed infant, noting that this type of interaction can soothe and calm the child and prevent prolonged periods of stress (2004). Witnessing in this instance is where value is located. Rymaszewska's notion of witnessing as a means of affirming validity of an experience, and Gerhardt's proposition that being present and responding to the vulnerable children can be soothing can both be applied to make the case for the teacher as witness. It could be suggested that the 
feedback from Mr Green is evidence of his continued affect on participants, i.e. the act of contributing to the performance by his students could be seen as a soothing act. The positive response that the teacher shared with his students may be considered a means of affirming the validity of his praise and appreciation of their performance in addition to his participation. This may have consolidated an alternative construction of the teacher as witnessed by his students thereby leading to sustained changes: continued positive peer and teacher interactions in the classroom. The authenticity of the encounter in the workshop may be responsible for this new way of 'knowing' one another.

C.A.J. Coady discusses the importance of testimony as the underlying source of knowledge $(1992,2002)$. Coady points out key debates regarding authenticity noting how testimony recounts affective and metaphorical readings of experiences and encounters that many theorists who critique the authenticity of testimony reject (see Collingwood 1970; Marshall 1966; Buckhout 1974). What is of particular significance in Coady's work is the argument for testimony to count as a valued form of knowledge or way of knowing the world. Discussing an example of the importance of hearing testimony, Coady suggests the following:

The judgements of others constitute an important, indeed perhaps the most important, test of whether my own judgements reflect a reality independent of my subjectivity (2002, 12).

Coady's statement notes our reliance on the judgements of others to understand an event or encounter from multiple perspectives. Understanding impact and value in the case study process relied upon the feedback or testimony of participants, not just in their spoken feedback but also shifts in interactions that both participants and I witnessed within workshops. Further to this, in relation to the value of this type of interaction and epistemology Coady relates the need to understand the contextual readings of events or encounters in relation to what constitutes value:

[...] we may be able to determine the meaning of a record or report in the sense of its social significance or role, even where we are uncertain of its reliability as a report of fact $(2002,237)$.

If we exchange a report and record for a witnessed encounter or recollection of a moment of importance in a workshop, what constitutes knowledge is the significance or value placed upon witnesses' experiences. The way of knowing what is conventionally seen as a form of measureable value in this sense is expanded to account for the potentially context-specific acknowledgement of value expressed by participants and witnesses. This may mean that impact as a measureable outcome that demonstrates our knowledge that change has taken place may need to be reconsidered. This reconsideration is not just in terms of the type of impact that is depicted but by the value of knowing determined by the testimony given in evaluation and consistent feedback from all who witness the process. Coady's work on the value of epistemology that draws upon, if not, predominantly relies upon testimony and therefore the role of the witness as a pathway to knowledge, is essential to understanding how participants in my research attributed worth and understood change within their encounters with participatory theatre practice.

\section{Conclusion: Implications for Future Impact Rhetoric and Research Limitations}

One of the main concerns highlighted at the start of this article was the contradictions of getting vulnerable youth to obey a system that is often discriminatory, particularly towards minority ethnic groups. The case study example I have unpacked, attempts to address this concern by not leading participants to conform to a system that is to their detriment, but instead shifting the constructs of those who convey the system as representatives of educational rhetoric. This article does not claim systemic change, but it does present a step forwards to shift constructs of vulnerable young people to ignite doubt in teachers who may feel that students hold limited potential, when surviving life is a struggle. Creating a space for change 
to transition using participatory theatre to alter perceptions through involving the teacher as witness may stop the spread of narratives of shame and blame that set up vulnerable young people to fail. Preventing the continued subtle communication of pathologies of failure may open possibilities for vulnerable youth to succeed.

The main challenge to consider is the timing of introducing and inviting the teacher as witness. In the case study, the presence of the teacher was at the request of the participants. Building the teacher as witness into a project timeline may be difficult to agree.

The case study also raises further questions about the appropriateness of inviting teachers as witnesses to a workshop. The process of how this may be agreed between participants and their teacher is important to consider further, alongside the potential implications of choosing the wrong moment for the teacher to witness their students. Another question to consider is the possibility that the encounter I have discussed was merely a happy accident. If this is the case then perhaps we cannot seek to replicate similar moments. More research is needed to understand whether or not this moment can be seen as valuable, and what value might mean in this context warrants further thought. Perhaps we need to continue thinking about an alternative perspective of what might constitute value in applied theatre in order to accept this incident as a 'little' but significant moment of change. An ethical dilemma to unravel is the potential negative impact that negotiating a teacher as witness may have on already strained relationships between a class teacher and their students. In which case, a careful consideration of the support needed to ensure this process is successful for both parties is essential to develop. It is also important to understand what other 'elements' were at play in this moment of practice that may have contributed to participants' taking the decision to invite their teacher in as a witness. If we can understand what enabled participants to come to this decision, we may be able to address several of the unanswered questions I have outlined.

Witnessing an event first hand and experiencing transformative processes with students may help to alter the perceptions of the teacher, particularly about the permanence of any shifts in interactions. It is not necessarily the experience of witnessing that recognises the longevity of change, but the consequence that the witness cannot deny what they see and thereby must reintegrate that knowledge into the production of the institutional structure through their future expectations of what is and what is not possible for their students. Teachers who have witnessed changes in the behaviour of their students, and students who are aware that their process has been seen by their teacher, have created new possible roles to play in the classroom. The teacher may have new expectations of the students in light of the process of the intervention, which may then be transferred to the students, an example of the Pygmalion Effect (Rosenthal \& Jacobson 1992). The process of the intervention may build more positive relationships between teachers and students. The potential of this shift in perception, if it were to be used in general pedagogical practice, may mean that vulnerable young people are no longer rendered socially immobile through institutional discrimination, and instead of feeling constraint, they may be able to escape the confines of pre-emptive constructs. The societal implications of this are unknown and further research is warranted to track the potential of this approach to see where it may lead. However, despite the limitations, perhaps the teacher choosing to witness his students, and students choosing to allow their teacher to witness their performance be an illustration of how a little change in approach may make all the difference. 


\section{Bibliography}

Balfour, Michael. 2009. The politics of intention: looking for a theatre of little changes, Research in Drama Education: The Journal of Applied Theatre and Performance, 14, No.3: 347-359.

Batmanghelidjh, Camila, 2006. Shattered Lives: Children Who Live with Courage and Dignity, London: Jessica Kingsley Publishers.

Bourgois, Phillipe. 2003. In Search of Respect: Selling Crack on the Streets of El Barrio, Cambridge, Cambridge University Press.

Brotherton, Graham, and Mark Cronin. 2013. Conclusion: Working with vulnerability? in Working with Vulnerable Children, Young People and Families, ed. Brotherton, G., and Cronin, M., 181-187, Abingdon: Routledge.

Coady, C.A.J. 2002. Testimony: A Philosophical Study, Oxford, Oxford University Press.

Denzin, Norman.K., and Yvonna S. Lincoln. 1998. Strategies of Qualitative Inquiry, London: Sage Publications Ltd.

Epskamp, Kees. 1989. Theatre in Search of Social Change: The relative significance of different theatrical approaches, Centre for the Study of Education in Developing Countries (CESO), The Hague.

Etherington, Kim. 2004. Becoming a Reflexive Researcher: Using Our Selves in Research, London: Jessica Kingsley Publishers.

Felman, Shoshana, and Dori Laub. 1992. Testimony: Crisis of Witnessing in Literature, Psychoanalysis, and history, Abingdon: Routledge.

Fisher, Tony. 2011. Radical Democratic Theatre, Performance Research, 16, No.4: 15-26.

Grady, Sharon. 2000. Drama and diversity: a pluralistic perspective for educational drama. Portsmouth: Heinemann.

Hill, Dave. 2007. Critical Teacher Education, New Labour, and the Global Project of Neoliberal Capital, Policy Futures in Education, 5, No.2: 204-225.

Jacobson, Lenore, and Robert Rosenthal. 1992. Pygmalion in the Classroom: Teacher Expectation and Pupils' Intellectual Development, Norwalk: Crown House sterl Publishing Company.

James, Adrian, and Allison James. 2004. Constructing Childhood: Theory, Policy and Social Practice, Basingstoke: Palgrave Macmillan.

James, Allison, and Chris Jenks. 1996. Public perceptions of childhood criminality, British Journal of Sociology, 47, No.2: 315-331.

James, Allison, Alan Prout. 2015. Constructing and Reconstructing Childhood: Contemporary Issues in the Sociological Study of Childhood, Abingdon: Routledge.

Kelly, George. A. 1963. A theory of personality: the psychology of personal constructs, New York: W.W. Norton \& Co.

Lambeth Council. 2012. Lambeth: State of the Borough 2012, https://www.lambeth.gov.uk/sites/default/files/State-of-the-borough-2012.pdf [Accessed 01/04/15].

Landy, Robert, David Montgomery. 2012. Theatre for Change: Education, Social Action and Therapy, Basingstoke: Palgrave Macmillan.

Macleod, Jay. 1987. Ain't No Makin' It: Aspirations and Attainment in a Low Income Neighborhood, London, Tavistock Publications Ltd.

Mr Green [pseud.]. 2009. Interview by Nicola Abraham. Digital recording. July 15. Greenlake School, London.

Mrs Rubens [pseud.]. 2009. Interview by Nicola Abraham. Digital recording. July 15. Greenlake School, London.

Muncie, John. 2009. Youth and Crime, $3^{\text {rd }}$ Edition, London, Sage Publications Ltd.

Österlind, Eva. 2008. Acting out of habits: can Theatre of the Oppressed promote change? Boal's theatre methods in relation to Boudieu's concept of habitus, Research in Drama Education, 13, No. 2: 71-82.

Participant Response [pseud.]. 2009. Interview by Nicola Abraham. Digital recording. July 15. Greenlake School, London. 
Phillips, Coretta. 2011. Institutional racism and ethnic inequalities: an expanded multilevel framework, The Journal of Social Policy, 40, No.1:173-192.

Preston, Sheila. 2011 Back on whose track? Reframing ideologies of inclusion and misrecognition in a participatory theatre project with young people in London, Research in Drama Education: The Journal of Applied Theatre and Performance, 16, No.2: $251-264$.

Reay, Diane. 2009. 'Making sense of white working class education underachievement', in K. P. Sveinsson (ed.), Who Cares About the White Working Class?, London: Runnymede Trust.

Rymaszewska, Janie. 2006. Reaching the Vulnerable Child: Therapy with Traumatized Children, London: Jessica Kingsley Publishers.

Sepinuck, Teya. 2013. Theatre of Witness: Finding the Medicine in Stories of Suffering, Transformation and Peace, London: Jessica Kingsley Publishers.

Wake, C. (2008) Through the (in)visible witness in Through the Wire, Research in Drama Education, 13, No.2: 187 - 192.

Weingarten, Kaethe. 2003. Common Shock: Witnessing Violence Every Day - How We Are Harmed, How We Can Heal, London: Dutton Penguin Books Ltd. 